\title{
Playing Computer Games to Learn, Train, and Improve Cognitively \\ Gamification of Life:
}

\author{
Dragana Martinovic ${ }^{1}$ \\ Robert Whent ${ }^{2}$ \\ Atinuke Adeyemi ${ }^{3}$ \\ Yuqi Yang ${ }^{4}$ \\ Christie I. Ezeife ${ }^{5}$ \\ Chrispina Lekule ${ }^{6}$ \\ Chantal M. Pomerleau ${ }^{7}$ \\ Richard A. Frost ${ }^{8}$
}

${ }^{1}$ University of Windsor, Canada

${ }^{2}$ OTEP, Inc., Canada

${ }^{3}$ University of Windsor, Canada

${ }^{4}$ University of Windsor, Canada

${ }^{5}$ University of Windsor, Canada

${ }^{6}$ University of Windsor, Canada

${ }^{7}$ University of Windsor, Canada

${ }^{8}$ University of Windsor, Canada

\section{Doi:10.5901/jesr.2013.v3n8p83}

\section{Abstract}

This paper describes various ways in which computer games may be used throughout life to achieve goals such as improved reaction time, reduced memory loss, or improved understanding of subject-related concepts. It also describes project conducted in our research lab, where we work on finding ways to measure and potentially improve children's cognitive processing (e.g., visual, auditory, and conceptual) through playing computer games. Our goals are to find the kind of cognitive effects, both major and minor, that specific computer games in our repository may have on children; find ways to evaluate a child's performance during play, taking into account the child's demographics, the gaming scores achieved, and time spent playing; relate the characteristics of the games and the child's performance in play to possible strengths and weaknesses in the child's cognitive processing; and to recommend remediation, in terms of the types of games that may be useful for the child to play next. Present state of our work is described, together with our short term and long term plans.

Keywords: cognition, serious games, cognitive games, brain fitness.

\section{Introduction}

Since their inception, computers were envisioned as tools for humans to use to do things faster and more accurately. Especially since when computers have found their place in educational institutions (at first mostly at universities and research centres) their use for educational purposes became standard (Keengwe, Kidd, \& Kyei-Blankson, 2009). Computers were also used in training skills (e.g., fast typing), various expert systems were developed to replace humans or enhance their performance, and after their cost became reasonable for individual to purchase and compact enough for home use, they also found their place in entertainment activities (Waycott, Bennett, 
Kennedy, Dalgarno, \& Gray, 2010).

Nowadays, in Canada, almost all youth use different types of information and communication technologies (e.g., Internet, handheld devices, etc.) with high frequency, and in most cases, daily (DeGennaro, 2008). All these technologies have games installed on them or easily accessible as shareware or for purchase. They can be used throughout life to achieve goals such as improved reaction time (Valadez \& Ferguson, 2012), reduced memory loss (Thorell, Lindqvist, Nutley, Bohlin, \& Klingberg, 2009), or improved understanding of subject-related concepts (Kebritchi, Hirumi, \& Bai, 2010). However, not all games are the same nor they were developed with a same purpose.

Some games are used in professional training (e.g., Gegenfurtner, Veermans, \& Vauras, 2013), for example in military, health care, and emergency management. Such games provide opportunities to act/react in imaginary situations that have high levels of reality. For example a nurse may practice inoculation in various situations and under various conditions; a soldier can practice decision making and reflexes in various war-like situations, and members of emergency rescue team can practice their collaborative actions and communication channels in disaster situations. While such games are not easy or cheap to develop, their return on investment is numerous including saving lives and resources, as well as providing opportunity to repeat training as many times as it is necessary.

The so called, serious games are also used for learning in the more traditional academic areas (e.g., mathematics, history, science). Such games need to align with a curriculum, and may be unattractive to students because they are perceived as "educational and not fun enough." Serious games usually display one of the two opposite characteristics: they may be two easy, trivial, and low key, or they may be too complex and difficult. Making a really attractive serious game means finding a proper balance between the two opposites and taking into account that users may have inadequate computers (especially since schools traditionally struggle with outdated technologies and limited technical support). In addition, although "serious" such games need to have the basic characteristics of games, such that make them appealing to the players in the first place-providing opportunities for winning or losing, for exploring and experimenting with different situations, and offering rewards. Such games may be used not only to brush up the skills and apply knowledge, but also as inspiration for conversation and for students to reflect on the choices they made. A student may be asked to demonstrate a game and discussion could be carried around the philosophy of the game, its design features, and a storyline; students could be asked to play different roles or characters/do tasks in the game, and explain how they made decisions.

Finally, games may be considered as a cognitive development tool, such that will provide players with transferable skills, and enhance their critical reasoning and self-regulation. Cognitive processes involve higher-level functions of the brain that encompass learning, language, imagination, perception, attention, and planning. Because children are attracted to playing computer games, it is important that these games help them develop cognitively.

\section{Literature Review: Playing Games and Cognition}

Today's frenetic progress in technology, communications, and change of lifestyle is affecting the way young brains develop, function, and process information, and is, in effect, creating new neural pathways and altering brain activity at a biochemical level. Ongoing statistics that follow changes in human cognitive development across generations reveal the so-called Flynn Effect (Martinez, 2010): Apparently, during the 20th century, Coefficients of Intelligence (IQs) in the U.S. increased by more than 20 points. Factors contributing to this change include improved basic living conditions (e.g., improved nutrition, spread of schooling) and, potentially, the increased complexity of living. It is evident that modern society is becoming progressively more saturated with all sorts of media, a situation that contributes to "informational complexity" (p. 342). This has prompted Neisser et al. (1996) to claim that "complexity of life has produced complexity of mind" (p. 90). 
At the same time, the U.S. national statistics confirm that about $20 \%$ of school children have some type of mental health issue (e.g., according to the U.S. Surgeon General, 2011). The Mental Health Commission of Canada (MHCC, 2011) states that $70 \%$ of adult mental health disorders originate in adolescence and that about $40 \%$ of youth have unidentified learning difficulties that affect their learning abilities (i.e., the acquisition, retention, and organization of information). Early screening of children's cognitive skills is critical for improved learning, academic success, and mental well-being (Volpe, Briesch, \& Chafouleas, 2010).

Playing computer and video games are lately being recognized as valid cognitive activities and are especially popular among children. In the literature, cognitive growth of children is often referred to by the Piagetian developmental stages, namely, concrete operational (ages 7 to 11) and formal operational (ages 11+) (Eastin, 2008). In attributing progression within and between stages to an increase in the child's information-processing capacity, Eastin cites Case's (1996) neoPiagetian developmental theory. It appears that as children age, their ability to store information in working memory improves, helping them to combine existing mental schemata as well as generating new ones, thus enabling them to think in a more advanced manner. Because children in the concrete operational stage have difficulty with abstractions, they have a propensity to reason based on physically tangible information (i.e., colours, sounds, animations, and images) and are likely to attend to the more appealing visual cues of the games. Cognitive development of children reflects their capability to self-regulate, make right decisions, and problem-solve. While computer games provide for multiple representations (e.g., visual, text, and sound) that are attractive, artistic, engaging, and fast-paced, they also put a strain on the cognitive load and attention span of the user, so all these aspects need to be taken into account for a child to benefit from playing games.

\section{Research Methods: Relation of Our Research to Brain Fitness}

Several research groups around the world investigate automated scoring mechanism as enhancement of learning. They also recommend using games for those purposes, mainly because new generations of children grew up with playing computer/video games and they enjoy a fastpaced, competitive nature of games with instant feedback and gratification. In essence, gaming is considered as problem solving and each aspect of solving the problem is recognized by increased score or increased level of the game.

We agree with Shute and Ventura (2013) that gaming may help children improve learning processes and outcomes; that strengths and weaknesses of the child may be identified to provide feedback for improvement of learning and outcomes. However, in order to achieve this goal, many unknowns need to be resolved first. Through our work, among else, we want to develop methodological tools for distinguishing different types of cognition that are involved in playing simple single-player games and to connect them to player's attributes that could be verified and measured during game play.

Shute and Ventura use the term "assessment" to describe measurement of the player's achievement on different aspects of the game. However, they are interested in the scores related to "educationally-relevant variables", such as thinking skill, creativity, and teamwork, while the game itself may involve other variables, such as how much treasure you have collected or how many dangers you have escaped. In our research we work with very simple games that are not educational because we want to target the essential cognitive skills in children. So, we need to distinguish between the major cognitive functions involved in playing each game in our repertoire, and find ways to evaluate child's performance in each game. In order to do so, we need to carefully analyze each game, but also look into all recordable aspects of the child's performance, such as time stayed on task, repetition of trials, looking for help, as well as performance per skill that is predominant in a cluster of the games. Also, the player's background information becomes relevant, such as age and gender. 
Our interpretation of cognitive skills is presented in the Online Training \& Education PortalOTEP Inc. Cognitive Matrix, consisting of 9 main cognitive categories (visual perception, visual attention, visual motor, auditory processing, executive function, memory, acquired cognition, social cognition, and emotional cognition) and 44 sub-categories (such as visual tracking, selective attention, visual motor integration, auditory perception, problem solving, semantic memory, language, phonics, reading comprehension, empathy, and relaxation).

Our interdisciplinary team uses the web site, Think-2-Learn.com, developed by the OTEP (see Whent et al., 2012), as the portal for parents, and DiscoveryGames.com which currently contains about 200 simple games. Each game was carefully selected because it was believed to target some aspect of cognitive processing in children.

In other related projects we have created a database that stores, searches, and retrieves gaming data. Such data will supply a feedback loop for recommendation of specific games to play. Such system could be used under a variety of conditions (e.g., in school or at home), could be designed to provide feedback to the child, parent, or professional (e.g., teacher, psychologist), and could work under different models (e.g., using behaviourist or cognitive model), based on the initial parameters that are selected by the person/team in charge of the system.

Given that the computer game play could be analyzed from different viewpoints, we decided to initially focus on (a) a specific player age, such as children 6-12 years old; (b) a specific type of games that are single-player, simple, and "cognitively responsible"; and (c) a specific purpose of the play, which is to help identify and measure cognitive development of the player. In our online repository, we presently have about 200 games. We call them "cognitively responsible" because we believe that each game most prominently engages two distinct cognitive functions in the player, with different intensity. In that way we classify each of our games according to the primary and secondary cognitive skill that it employs, together with their sub-categories (see Table 1).

Table 1. Sample primary and secondary cognitive categories and their sub-categories for two games in the repository.

\begin{tabular}{ccccc}
\hline Game & $\begin{array}{c}\text { Primary Cognitive } \\
\text { Category }\end{array}$ & $\begin{array}{c}\text { Cognitive } \\
\text { Sub-category }\end{array}$ & $\begin{array}{c}\text { Secondary Cognitive } \\
\text { Category }\end{array}$ & $\begin{array}{c}\text { Cognitive } \\
\text { Sub-category }\end{array}$ \\
\hline $\begin{array}{c}\text { Bobo Snake (action } \\
\text { game, see Figure 1) }\end{array}$ & Visual Perception & $\begin{array}{c}\text { Spatial } \\
\text { Judgement }\end{array}$ & Visual Motor & $\begin{array}{c}\text { Visual Motor } \\
\text { Integration }\end{array}$ \\
$\begin{array}{c}\text { Wolf, Sheep and } \\
\begin{array}{c}\text { Cabbage (logic game, } \\
\text { see Figure 1) }\end{array}\end{array}$ & $\begin{array}{c}\text { Executive } \\
\text { Functioning }\end{array}$ & $\begin{array}{c}\text { Reasoning } \\
\text { Tasks }\end{array}$ & $\begin{array}{c}\text { Executive } \\
\text { Functioning }\end{array}$ & Problem Solving \\
\hline
\end{tabular}
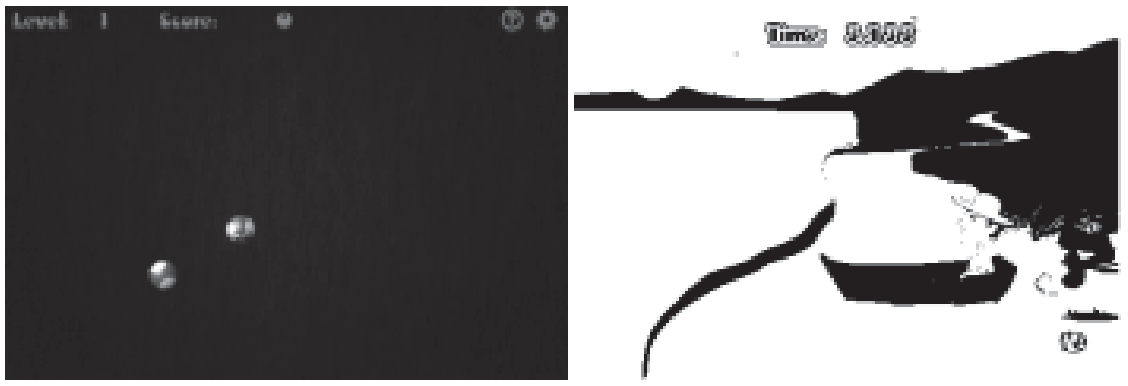

Figure 1. Screen shots of Bobo Snake (on the left) and Wolf, Sheep, and Cabbage (on the right).

Our working hypotheses are that the simple computer games involve identifiable cognitive functions and that the player's performance during gaming may help identify his/her cognitive 
strengths and weaknesses, which could be then used to determine further human or software intervention (e.g., recommend which other games to play, or see Partala \& Surakka, 2003).

Because of our methodological approach and sensitivity of the outcome (e.g., creating a cognitive profile of a person based on his/her game play), reliably relating computer games to the player's cognitive functions is crucially important. We approached this task by first having a Neuropsychologist on our team identify two cognitive functions engaged in each game; then, 12 individual raters were invited to play games and identify to which categories they belong to, as well as to evaluate relevance of the psychologist's categorization. Through this process, we were able to see if our games clearly relate to the stated cognitive functions, if definitions of the cognitive functions are easy to follow and are accurate, to identify games that may be problematic for this categorization and definitions that are confusing (or inadequate), and to prepare information for the software engine that our team is building.

The outcome of our analysis is that we removed 15 games from our repository, clarified definitions of cognitive skills, and found that our raters agreed among themselves and with the psychologist in more than $75 \%$ of the remaining games. Our goal is to integrate the attributes of the remaining games in the repository with the child's age and gender and performance during play (time spent playing a game or solving specific game challenges, errors made, use of help function in the game, and areas of success in the game, as suggested by Lieberman et al., 2009). Storing this information in a database will allow us to quickly analyze the data and will establish a foundation for our future work of making recommendations for improving cognitive processing through playing games.

\section{Next Steps in Our Work}

The overarching hypothesis of our project described in this paper is that a cognitive profile of a child can be ascertained and potentially improved upon by the child playing a large number of simple computer games over a period of time. The computer games being used in this study have been categorized as engaging the player's primary and secondary cognitive functions by a clinical neuropsychologist and reliability of this evaluation was vetted through our research.

A rationale driving this study is that if a child plays a series of working memory games and scores lower in these games than other children of his/her age (deviates much below from the normative data), it stands to reason that this child may have a weakness in this cognitive category. In the next stage of our study, we are going to test a small sample of children first with a qualified psychological instrument in a controlled environment with the child's parent present. This will give us a baseline analysis of the child's cognitive areas of strengths and weaknesses. The parent will complete a questionnaire that asks about the child behaviour, learning, and aspects of cognition.

We will then have the children play 15 of the cognitively categorized games. Children will be asked to play each game three times; once to learn how to play the game, and second and third time to obtain the more accurate measurement of game performance. Through this process, we are hoping to test the hypothesis that there exists a positive correlation between the qualified psychological instrument results and child's performance in the games that belong to corresponding cognitive categories. Further to our example, we expect that a child identified through traditional psychological tests as having weak working memory, will perform poorly on the cluster of the working memory games.

\section{Conclusion}

The approach we are taking in our research has opened new possibilities for methodologies in game studies and has defined new and exciting areas for implementation of computer games in learning, skill development, and cognitive exercise that we will be further pursuing. The potential contribution of this research lies in our analysis of the data to work out principles of game design 
that can help make games more developmentally appropriate and beneficial by building on the ways schoolchildren naturally play and learn.

We expect this research will help to (1) address existing societal concerns about the possible negative effects of computer games on children's cognitive development; (2) encourage academics, teachers, and parents to collaborate with the gaming industry in developing appropriate computer games; and (3) provide new methods and instruments for future research in this area.

Our research will be of interest to educators, psychologists, and computer scientists. Our findings will also interest youth workers and parents, many of whom are worried about the assumed negative effects of video and computer games on children.

\section{References}

Abdullah, M.R.T.L., Bakar, Z.A., Ali, R.M., Faye, I., \& Hasan, H. (2012). The impact of video games in children's learning of mathematics. World Academy of Science, Engineering and Technology, 64, 968-974.

DeGennaro, D. (2008). Learning designs: An analysis of youth-initiated technology use. Journal of Research on Technology in Education, 41(1), 1-20.

Gegenfurtner, A., Veermans, K., \& Vauras, M. (2013). Effects of computer support, collaboration, and time lag on performance self-efficacy and transfer of training: a longitudinal meta-analysis. Educational Research Review, 8, 75-89.

Griffiths, M.D. (1996). Computer game playing in children and adolescents: A review of the literature. In T. Gill (ed.) Electronic children: how children are responding to the information revolution (pp. 4158). London: National Children's Bureau.

Eastin, M.S. (2008). Toward a Cognitive Development Approach to Youth Perceptions of Credibility. Digital Media, Youth, and Credibility. In M.J. Metzger and A.J. Flanagin (eds.), The John D. and Catherine T. MacArthur Foundation series on digital media and learning (pp. 29-48). Cambridge, MA: The MIT Press.

Keengwe, J., Kidd, T., \& Kyei-Blankson, L. (2009). Faculty and technology: Implications for faculty training and technology leadership. Journal of Science Education and Technology, 18(1), 23-28.

Kebritchi, M., Hiruni, A., \& Bai, H. (2010). The effects of modern mathematics computer games on mathematics achievement and class motivation. Developmental Science, 55(2), 427-443.

Lieberman, D., Fisk, M., \& Biely, E. (2009). Digital games for young children ages three to six: From research to design. Computers in the Schools, 26(4).

Martinez, M. (2010). Learning and cognition: The design of the mind. Upper Saddle River, NJ : Pearson Education.

MHCC (2011). Child and youth mental health newsletter. Retrieved June, 2013, from http://cts.vresp.com/c/?MentalHealthCommissi/59cd7fd342/TEST/86d3d3a333

Neisser, U., Boodoo, G., Bouchard, T.J., Boykin, A.W., Brody, N., Ceci, S.J., Halpern, D.F., Loehlin, J.C., Perloff, R., \& Sternberg, R.J. (1996). Intelligence: Knowns and unknowns. American Psychologist, 51(2), 77-101.

Partala, T., \& Surakka, V. (2003). The effects of affective interventions in human-computer interaction. Interacting with Computers, 16, 295-309.

Shute, V., \& Ventura, M. (2013). Stealth assessment: Measuring and supporting learning in video games. Cambridge, MA: MIT Press.

Subrahmanyam, K., Kraut, R.E., Greenfield, P.M., \& Gross, E.F. (2000). The impact of home computer use on children's activities and development. The Future of Children - Children and Computer Technology, 10(2), 123-144.

The U.S. Surgeon General (2011). National prevention strategy. Retrieved from http://www.healthcare.gov/prevention/nphpphc/strategy/report.pdf

Thorell, L.B., Lindqvist, S., Nutley, S.B., Bohlin, G., \& Klingberg, T. (2009). Training and transfer effects of executive functions in preschool children. Developmental Science, 12(1), 106-113. 
Valadez, J.J., \& Ferguson, C.J. (2012). Just a game after all: Violent video game exposure and tie spent playing effects on hostile feelings, depression, and visuospatial cognition. Computers in Human Behavior, 28(2), 608-616.

Waycott, J., Bennett, S., Kennedy, G., Dalgarno B., \& Gray, K. (2010) Digital divides? Student and staff perceptions of information and communication technologies. Computers \& Education, 54(4), 12021211.

Whent, R., Martinovic, D., Ezeife, C.I., Ahmed, S., Alahmad, Y., \& Mumu, T. (2012). School age children's cognition identification by mining integrated computer games data. The $4^{\text {th }}$ International Conference on Computer Supported Education, CSEDU 2012, 16-18 April, 2012, Porto, Portugal, 495-505. 
